\title{
DESIGN OF ION SOURCE FOR LANSCE UPGRADE*
}

\author{
M. Williams, R. Gough, K. Leung, R. Low, C. Matuk, R. Thomae, S. Wilde \\ E. O. Lawrence Berkeley National Laboratory, Berkeley, CA 94720
}

\begin{abstract}
The upgrade of the Los Alamos Neutron Science Center (LANSCE) Facility will require high intensity $\mathrm{H}^{-}$beams. Lawrence Berkeley National Laboratory (LBNL) has been contracted by Los Alamos to develop an $\mathrm{H}^{-}$ion generator that will meet the LANSCE upgrade requirements. $\mathrm{H}^{-}$ current is to be increased from the present $18 \mathrm{~mA}$ to 40 $\mathrm{mA}$. The current LANSCE ion source uses surface conversion process and extracts ions radially. Two tungsten filaments are used as cathodes. The ion source designed by LBNL is also a surface conversion type source but the ions are extracted axially. This design allows six or more tungsten filaments to be installed radially so that the magnetic field of the permanent magnets on the cylindrical wall provides a magnetic filter field. This filter field prevents energetic electrons from entering the central plasma region where they could strip the $\mathrm{H}^{-}$ions. The LBNL designed ion source has been operated successfully at the design parameters, $40 \mathrm{~mA} \mathrm{H}^{-}$at $12 \%$ duty factor with $1 \mathrm{msec}$ pulses. This paper describes the design and fabrication of the ion source.
\end{abstract}

\section{INTRODUCTION}

The next generation spallation neutron sources, such as the upgrade of the Los Alamos Neutron Science Center (LANSCE) Facility will require high intensity negative hydrogen $\left(\mathrm{H}^{-}\right)$beams. Lawrence Berkeley National Laboratory has been contracted by Los Alamos National Laboratory to develop an $\mathrm{H}^{-}$ion generator that can meet the upgrade LANSCE neutron source requirement. Specifically, the output current of the new $\mathrm{H}^{-}$ion source has to increase from 16 to $40 \mathrm{~mA}$. In addition, source emittance, reliability, and availability will need to be improved. All of which must be achieved while operating under the facility's prescribed $12 \%$ duty factor (1 ms pulse at $120 \mathrm{~Hz}$ ).

In order to meet the LANSCE source requirement, the Ion Beam Technology (IBT) Program at LBNL chose the surface-conversion multicusp ion source as the base candidate. The present LANSCE $\mathrm{H}^{-}$source is also a surface-conversion source, however the $\mathrm{H}^{-}$output current does not increase much beyond $20 \mathrm{~mA}$ with higher discharge power. ${ }^{1}$ Previous experimental study at LBNL demonstrated that if the surface-conversion source is operated with a magnetic filter, the $\mathrm{H}^{-}$output current generated by a barium converter can increase without saturation with increased discharge power. ${ }^{2}$ Based on this study, a prototype ion source has been developed to utilize the multi-cusp magnet arrangement as a filter. Cesium is used to lower the work function of the converter and therefore enhance the $\mathrm{H}^{-}$yield. .

\section{ION SOURCE CONFIGURATION}

LBNL has been developing multicusp surface conversion ion sources for many years. ${ }^{3,4}$ The typical multi-cusp $\mathrm{H}^{-}$ surface conversion source consists of a plasma chamber and a negatively-biased converter electrode as illustrated in Figure 1.

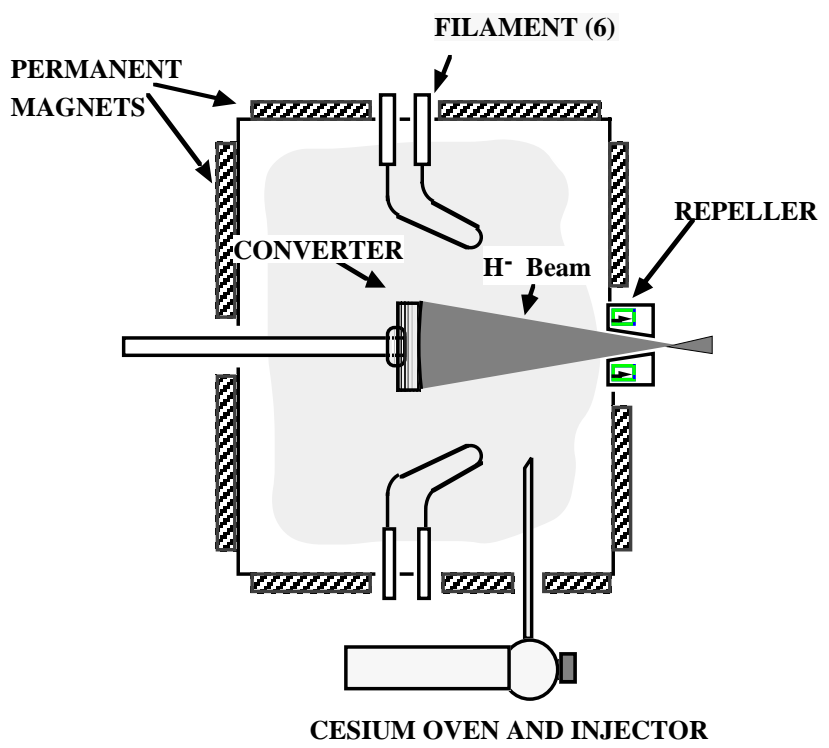

Figure 1: Schematic of the surface conversion ion source.

The positive ions present in the hydrogen plasma $\left(\mathrm{H}^{+}\right.$, $\mathrm{H}_{2}^{+}, \mathrm{H}_{3}^{+}$) are accelerated across the plasma sheath formed along the converter surface. $\mathrm{H}^{-}$ions are formed on the surface and extracted back across the sheath. The spherical surface of the converter focuses the negative ions through the extraction aperture. The converter is coated with a low work-function material such as cesium to enhance negative ion conversion.

The current LANSCE ion source has a cylindrical body and the negative ions are extracted radially. The two filament cathodes are located on the cylinder end flanges.

The new LANSCE $\mathrm{H}^{-}$ion source is also of cylindrical design, however, the converter is installed along and parallel to the cylindrical axis as shown in Figure 2. Negative ions are extracted along the cylindrical axis. Six filaments are installed radially between the cylindrical wall cusp magnets, Figure 3. The magnets provide a filter field, which reduces the number of energetic electrons in the main plasma volume. This reduces the negative ion stripping due to energetic electrons. A converter of twice 
the area of the current converter is also used. The radius of curvature is increased to maintain the same projection angle. The axial position of the converter was optimized for maximum $\mathrm{H}^{-}$output.

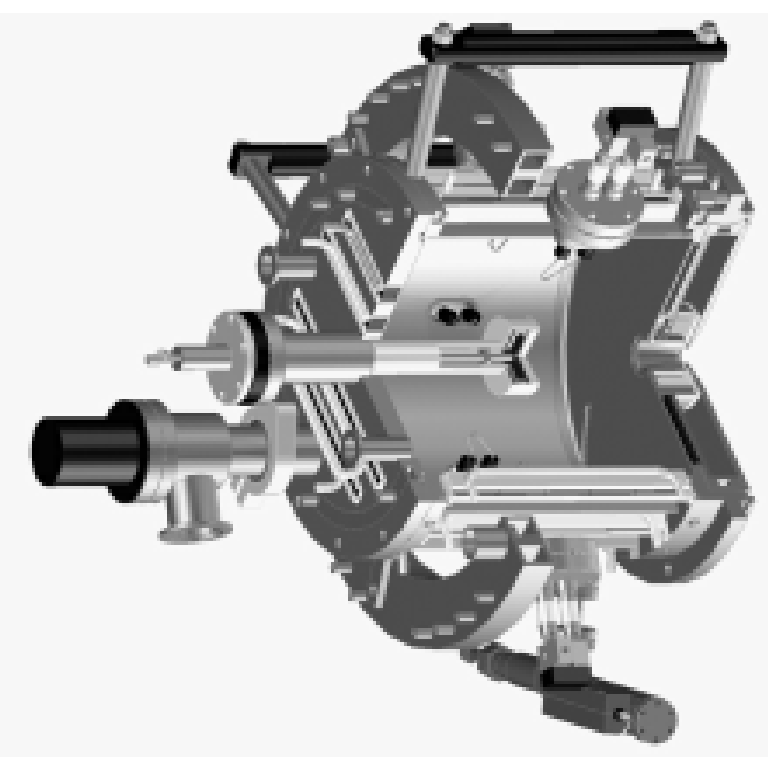

Figure 2: 3-D cutaway rendering of the LBNL designed ion source for LANSCE. Note that the filaments are placed radially and the converter al mounted along and parallel to the cylindrical axis.

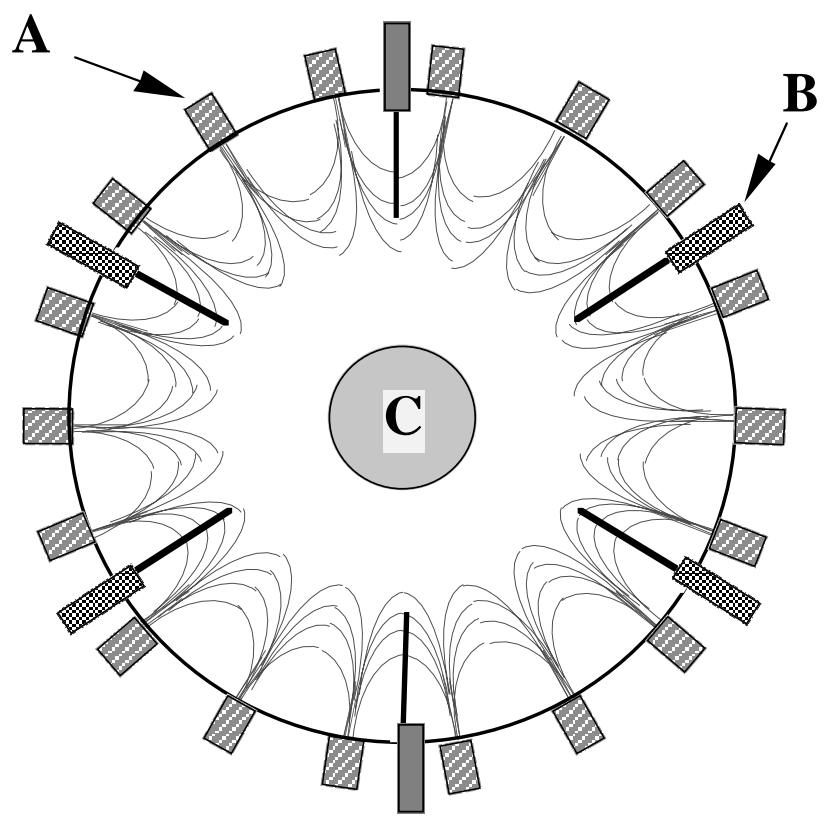

Figure 3: Magnet and filament configuration. (A) Wall cusp magnets (18 columns). (B) Filaments (total 6). The filament tips are placed at approximately the 25 gauss region. (C) Converter installed on the cylindrical axis.

A repeller similar to one used on the current LANSCE source is utilized in the new design to prevent electrons from being extracted and accelerated along with the primary $\mathrm{H}^{-}$beam, Figure 1. This is an electrically isolated, conical collimator installed in front of the outlet aperture. The collimator is biased slightly positive with respect to the ion source body. This repels positive ions. The lack of positive charge in the region will prevent plasma electrons from entering. Two magnets form a cusp field within the collimator to deflect energetic electrons from the converter to the conical wall.

Cesium is injected into the source from a heated oven. The oven is mounted on the cylindrical wall with an injection tube penetrating the This arrangement enables one to inject cesium into the central plasma region. Cesium forms a thin layer on the converter, which enhances $\mathrm{H}^{-}$conversion. The operating temperature is typically between 200 and $300 \mathrm{C}^{\circ}$.

\section{ION SOURCE CONSTRUCTION}

The ion source body is constructed of stainless steel. It is cylindrical with plasma confinement provided by samarium cobalt magnets placed on all source walls. The cylindrical sidewall has 18 line cusps parallel to the source axis. The rear flange has four line cusps placed on parallel chords. The front flange has 18 radially arranged magnets. A space is provided in the center of the radial array for installation of the repeller assembly. The wall and back flange magnets are installed in copper boats to provide cooling. The front flange magnets are mounted on a low carbon steel plate, which is brazed to a copper plate. The copper plate is in turn attached to the main water-cooled flange.

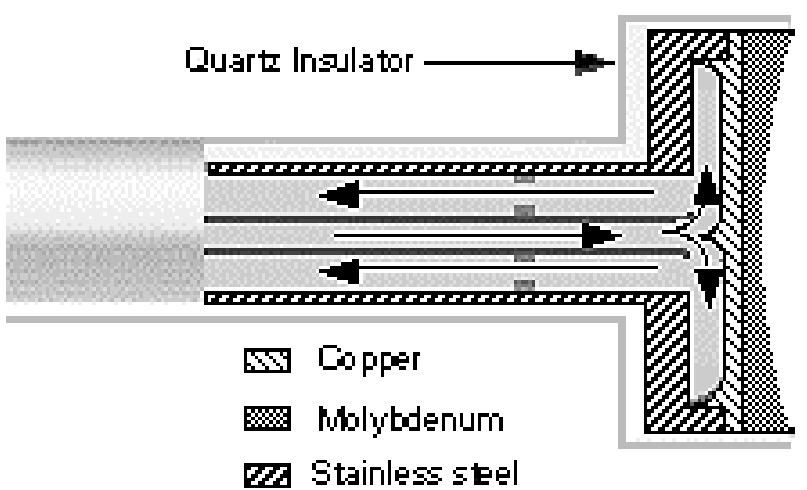

Figure 4: Cross-section schematic of the converter showing construction and water flow.

The converter is installed through the rear flange. An insulating flange is used to provide electrical isolation from the source body. Figure 4 is a schematic of the converter construction. The converter surface is machined to a spherical shape from molybdenum. The molybdenum plate is vacuum brazed to a copper interface piece to provide good thermal contact and conductance to the cooling channel. The cooling channel is machined from stainless steel and is vacuum brazed to the copper. Coaxial stainless steel tubing is welded to the cooling channel 
plate. Water is supplied through the inner tube and returned through the outer. A quartz cover is provided for the rear and side surfaces of the converter assembly. The cover isolates the areas which face the plasma. Only the spherical surface is exposed to the plasma.

Six filament feedthroughs are provided. They are arranged radially around the cylindrical wall. Cooling is provided by squirt tubes inserted in each feedtthrough leg. The filaments are fabricated from $1.5-\mathrm{mm}$ diam. tungsten rod. The filaments are inserted into and held firmly by a molybdenum and copper chucks.

A cesium oven connected to a commercial high temperature valve is installed radially on the cylindrical wall. A molybdenum tube is used to transport cesium vapor into the central region of the ion source. A heating block is mounted on the oven. It is heated by a 250 Watt cartridge heater.

\section{CONCLUSION}

Two ion identical ion sources have been fabricated. Figures 5 and 6 are photographs of one of the sources. One has been delivered to LANSCE for testing on their test stand. The second source is being tested on the LBNL test stand.

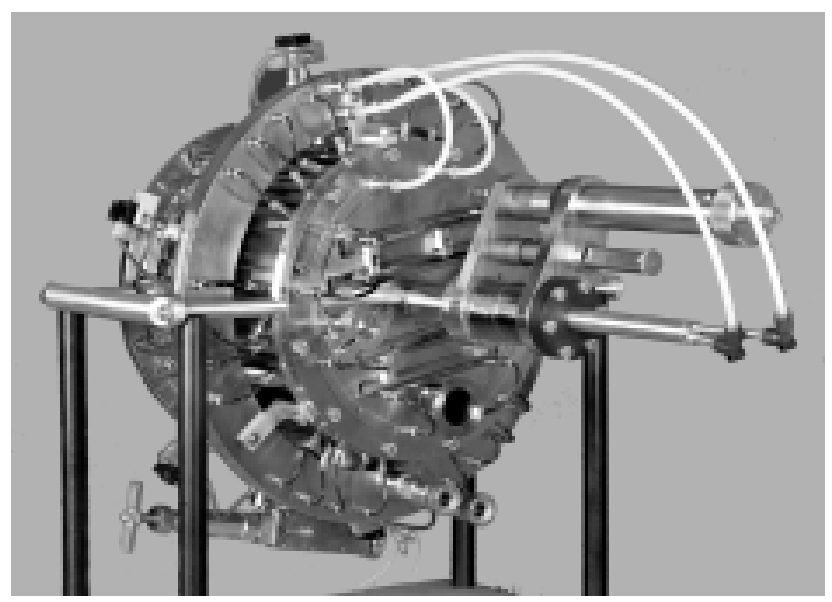

Figure 5: Photograph showing the back flange of the ion source. The linear manipulator is for test purposes only. It will be used to optimize the converter position for optimum current and emittance.

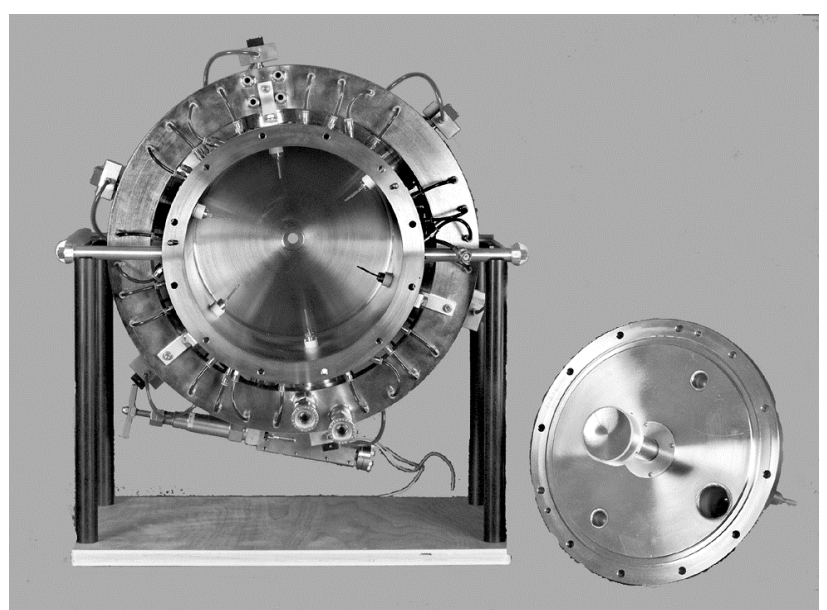

Figure 6: Photograph showing inside of the ion source. The converter can be seen on the removed end flange. Notice the six radially positioned filaments.

\section{ACKNOWLEDGMENTS}

We would like to thank S. B. Wilde, P. J. Rosado, T. A. McVeigh, P. Wong and L. W. Mills for their technical assistance.

* This work was supported by Los Alamos National Laboratory and the U.S. Department of Energy under Contract No. AC03-76SF00098

\section{REFERENCES}

[1] R. R. Stevens Jr., R.L. York, R. Kendarian, Proceedings of the 1984 Linear Accelerator Conference.

[2] C.F.A. van Os, K. N. Leung, and W. B. Kunkel Appl. Phys. Lett. 57 (9), 27 Aug. 1990.

[3] K. W. Ehlers and K. N. Leung, Rev. Sci. Instrum. 51, 721 (1980).

[4] K. W. Ehlers and K. N. Leung, Rev. Sci. Instrum. 53(6), 803 (1982). 